\title{
Review Article \\ Recent Advances in the Deposition of Diamond Coatings on Co-Cemented Tungsten Carbides
}

\author{
R. Polini, ${ }^{1}$ M. Barletta, ${ }^{2}$ G. Rubino, ${ }^{2}$ and S. Vesco ${ }^{2}$ \\ ${ }^{1}$ Dipartimento di Scienze e Tecnologie Chimiche, Università degli Studi di Roma Tor Vergata, Via della Ricerca Scientifica, \\ 00133 Roma, Italy \\ ${ }^{2}$ Dipartimento di Ingegneria Meccanica, Università degli Studi di Roma Tor Vergata, Via del Politecnico, 00133 Roma, Italy
}

Correspondence should be addressed to M. Barletta, barletta@ing.uniroma2.it

Received 2 June 2012; Accepted 13 August 2012

Academic Editor: Pavel Lejcek

Copyright (c) 2012 R. Polini et al. This is an open access article distributed under the Creative Commons Attribution License, which permits unrestricted use, distribution, and reproduction in any medium, provided the original work is properly cited.

\begin{abstract}
Co-cemented tungsten carbides, namely, hard metals are largely used to manufacture high wear resistant components in several manufacturing segments. Coating hard metals with superhard materials like diamond is of utmost interest as it can further extend their useful lifespan. The deposition of diamond coatings onto WC-Co can be extremely complicated as a result of poor adhesion. This can be essentially ascribed to (i) the mismatch in thermal expansion coefficients between diamond and WC-Co, at the typical high temperatures inside the chemical vapour deposition (CVD) chamber, generates large residual stresses at the interface; (ii) the role of surface Co inside the WC-Co matrix during diamond CVD, which promotes carbon dissolution and diffusion. The present investigation reviews the techniques by which Co-cemented tungsten carbides can be treated to make them prone to receive diamond coatings by CVD. Further, it proposes interesting ecofriendly and sustainable alternatives to further improve the diamond deposition process as well as the overall performance of the coated hard metals.
\end{abstract}

\section{Introduction}

Co- $(5.8 \%$ wt. $)$ cemented tungsten carbides belong to the class of hard metals, widely used for the manufacturing of cutting tools, sliding bearings, drawing dies, and a large variety of wear-resistant components. High temperature chemical vapor deposition (CVD) of diamond coatings onto Co-cemented tungsten carbide (WC-Co 5.8\% wt.) is a highly effective procedure to further increase the useful lifespan of hardmetal components by application on them of a superhard and chemically inert thin layer. Yet, the diamond deposition process is affected by several drawbacks. These are essentially ascribable to the onset of large residual stresses in the coating due to the mismatch in the thermal expansion coefficients between diamond and WC-Co and to the presence of the Co-based binder. Co can interact with the gas phase at high temperature during chemical vapor deposition (CVD), be quickly saturated with $C$ [1] and promote the growth of an intermediate graphitic layer on which poorly adherent diamond can grow [2]. The deleterious effect of Co can be taken aback by removing it from the outermost layers of WC-Co using multistep etching procedures involving aggressive chemicals [3]. Ti-, Si-, and Cr-based interlayers deposited by physical vapor deposition (PVD) have also been reported to improve the growth of diamond coatings onto WC-Co [4]. The interlayers are deposited on the WCCo substrate and act as $\mathrm{C}$ and Co diffusion barrier during the CVD process. They also interpose themselves between the WC-Co and diamond reducing the mismatch in their thermal properties [5]. Among the interlayers, the Cr-based ones play a special role. Metallic chromium (Cr) interlayers alone cannot sustain the diamond coatings and further mechanical treatments (i.e., shot or fluidized bed peening) to corrugate them and increase the diamond adhesion are of crucial importance [6]. Indeed, mechanically treated $\mathrm{Cr} / \mathrm{CrN}$ and $\mathrm{CrN}$ interlayers seem to be very competitive although a very high time and cost consuming procedure is needed to deposit and, eventually, mechanically treat them. Thermal treatments of as-ground WC-Co are aimed at modifying the substrate morphology, reducing Co concentration at the interface and reducing some kind of surface reconstruction $[7,8]$. Thermochemical treatments can be a viable alternative 
as they could promote the conversion of Co in, for example, $\mathrm{CoB}$, which is chemically inert during CVD [9]. Among the large variety of thermal treatments, laser treatments play a very important role, too. Pulsed laser sources can reduce Co concentration in the outermost layers of the WC-Co, promote their surface corrugation, and improve the adhesion on them of the diamond coating by mechanical interlocking [8]. Nonetheless, pulsed source is operated at high laser irradiance $\left(>80 \mathrm{MW} / \mathrm{cm}^{2}\right)$. Rather than selectively remove $\mathrm{Co}$, they tend to remelt the substrate material and give rise to a sort of massive surface reconstruction [10]. The final results are a macrocorrugated morphology with rather flat peaks, composed of WC and hollow valleys in which some excess of Co is still present. Moreover, some Co and W oxides can be generated at such temperature, if any caution to protect the WC-Co from oxygen is not taken [10]. Accordingly, pulsed laser source has always been associated to further treatments like etching with dilute acid solutions to remove Co excess, eventually, most of the oxides and, thus, allow the deposition of diamond films [10]. Recently, continuous diode lasers in argon and nitrogen atmosphere are showed to be effective to selectively remove the Co-binder form WC-Co substrate, promote the establishment of a layer rich in WC and, thus, with thermal expansion coefficient close to diamond and avoid further substrate pre-treatments $[11,12]$. Such laser treatments are also found to be very promising to prepare the WC-Co substrates to the application of diamond coatings by CVD [12].

This is the context in which the present investigation moves to report some of the recent advances of the technology to make the Co-cemented tungsten carbides ready to diamond deposition by CVD. Further, wear resistance and adhesive toughness of diamond coated Co-cemented tungsten carbides for some selected scenarios of growing industrial interest are also discussed into details.

\section{Methodology}

The most widespread technique to pre-treat Co-cemented tungsten carbides prior to diamond CVD is by single or multi-step etching procedures with aggressive chemicals [1315]. Chemical etching is generally performed in aqueous solution of either strong oxyacids or hydrochloric acid as well as by multi-step procedures, which etch Co out of WC-Co surface and corrugate the substrate. A typical example of simple single step etching procedure involves the use of concentrated nitric acid for rather long time (10 to $15 \mathrm{~min}$ ) to remove Co from the surface of the WC-Co substrates. Chemical etching is usually followed by abrasion of the etched substrate by $1-3 \mu \mathrm{m}$ abrasive powders to increase the surface contact area between the substrate and the overlying coating, thus promoting their adhesion by mechanical interlocking [13]. An example of multi-step procedure is the so-called Murakami's Treatment [14]. The procedure involves a first step in which the Co-cemented tungsten carbides are etched with a solution composed of potassium iron cyanide and potassium hydroxide in water $\left(10 \mathrm{~g} \mathrm{KOH}+10 \mathrm{~g} \mathrm{~K}_{3}\left[\mathrm{Fe}(\mathrm{CN})_{6}\right]+100 \mathrm{~mL}\right.$ water $)$ for about
$60 \mathrm{~s}$. The second step is a chemical etching of the substrate by Caro's acid, that is, a solution of sulfuric acid in hydrogen peroxide (3 $\mathrm{mL} 96 \mathrm{wt} . \% \mathrm{H}_{2} \mathrm{SO}_{4}+88 \mathrm{~mL} 40 \% \mathrm{w} / \mathrm{v} \mathrm{H}_{2} \mathrm{O}_{2}$ ) for very short time ( $10 \mathrm{~s}$ or less). This way, Co removal and corrugation of the WC-Co substrate can be concurrently achieved.

The application of interlayers between Co-cemented tungsten carbides and diamond coatings is also widely spread in the scientific literature, although it is rather unusual in the industry practice for the very large time and cost consuming procedures they need to be applied. A wide range of interlayer materials (amorphous carbon, metallic $\mathrm{Cr}$, $\mathrm{Ti}$, $\mathrm{Ta}$, and so forth and ceramic $\mathrm{CrN}, \mathrm{TiC}, \mathrm{TiN}, \mathrm{SiC}$, and $\mathrm{Si}_{3} \mathrm{~N}_{4}$ ) can be successfully applied by physical or chemical vapor deposition on WC-Co substrates. PVD arc with chamber pressure of 1-2 $\mathrm{Pa}$ and deposition temperature of $350-450^{\circ} \mathrm{C}$ has been reported to deposit $\mathrm{Ti}$ and Cr-based interlayers [16]. In this case, typical gas phase includes pure $\mathrm{N}_{2}$ for TiN and $\mathrm{CrN}$ interlayers, mixture rich in $\mathrm{Ar}(>70 \%)$ with some $\mathrm{CH}_{4}(\sim 15-30 \%)$ for $\mathrm{TiC}$ and $\mathrm{CrC}$ interlayers and mixture rich in $\mathrm{N}_{2}(\sim 85 \%)$ with some $\mathrm{CH}_{4}(\sim 15 \%)$ for $\mathrm{Ti}(\mathrm{C}, \mathrm{N})$ interlayers. Typical thicknesses of the PVD films range from few to 10 microns. Ti-based interlayers on WC-Co substrate deposited by unbalanced magnetron sputtering have also been reported in the literature [17]. SiC interlayers applied on WC-Co substrates by chemical vapor deposition, with tetramethylsilane (TMS) as single-source precursor for both silicon and carbon, are often reported in the literature [18]. Typical gas phase involves $0.1 \%$ TMS in hydrogen, chamber pressure of $500 \mathrm{~Pa}$ and substrate temperature of $780^{\circ} \mathrm{C}$. The deposition was therefore performed at high temperature, although, recently, novel low temperature deposition process was introduced [19].

Corresponding coating thicknesses can range from 0.5 to $1 \mu \mathrm{m}$. TiN, $\mathrm{Si}_{3} \mathrm{~N}_{4}, \mathrm{a}-\mathrm{SiC}, \mathrm{a}-\mathrm{SiC}_{x} \mathrm{~N}_{y}, \mathrm{a}-\mathrm{C}, \mathrm{TiB}_{2}, \mathrm{Mo}, \mathrm{Ti}$ and $\mathrm{W}$ deposited by plasma assisted chemical vapor deposition (PACVD) on Co-cemented tungsten carbide have also been documented in the scientific literature [20-22].

Thermal or thermochemical treatments are viable and industrially attractive alternatives to pretreat Co-cemented tungsten carbides before diamond CVD. For example, decarburizing of tungsten carbides by plasma CVD in $\mathrm{H}_{2}-\mathrm{O}_{2}$ atmosphere followed by recarburizing in $\mathrm{CH}_{4}-\mathrm{H}_{2}$ atmosphere is one of the simplest techniques to promote the growth and improve the adhesion of diamond coatings on WC-Co substrates. Such treatments are usually performed at temperature of 900 to $1000^{\circ} \mathrm{C}$ with chamber pressure of $4-5 \mathrm{kPa}$ [23]. Further approaches involve heat treating the WC-Co substrate for a time, at a temperature and in a protective atmosphere that produces WC grain growth at the surface, increases roughness without forming subsurface porosity, and virtually eliminates surface cobalt by evaporation. The specific heat-treating conditions must be tailored to the cobalt content of the WC-Co alloy [24]. Thermochemical treatments involve plasma nitriding and carbonitriding as well as plasma boronitriding. Plasma nitriding and carbonitriding can be carried out in r.f. induction plasma. The usual conditions of plasma nitriding and carbonitriding are as follows: $45 \mathrm{~Pa}$ gas pressure, 
$\mathrm{N}_{2}: \mathrm{C}_{2} \mathrm{H}_{2}=100: 0 \sim 90: 10$ gas composition, $450-900^{\circ} \mathrm{C}$ substrate temperature, $5 \mathrm{~kW}$ plasma power [25]. Plasma boronitriding can be carried out in a microwave plasma. Boron oxide was generally used as the boron source. The plasma boronitriding conditions are as follows: substrate temperature, $800^{\circ} \mathrm{C} ; \mathrm{H}_{2}-\mathrm{NH}_{3}$ atmosphere; gas pressure, $5.4 \mathrm{kPa}$; temperature of boron oxide is approximately lower $200-250^{\circ} \mathrm{C}$ than that of the substrate; boronitriding time, $0.5-2 \mathrm{~h}$; microwave power, $700-1500 \mathrm{~W}$ [26]. Laser treatments belong to the class of thermal treatments. Pulsed laser sources are mostly applied to modify the surface of the Co-cemented tungsten carbides, using a repetitive pulsed excimer laser irradiation process $(\lambda=250-300 \mathrm{~nm}, \tau=20$ $25 \mathrm{~ns}$ ) [27-29]. Incident laser energies are usually varied from 2 to $8 \mathrm{~J} / \mathrm{cm}^{2}$ and the number of pulses from 100 to $800[27,28]$. Etching with chemical solutions is often needed to remove oxides and/or contaminants which are generated during laser treatments [29]. $940 \mathrm{~nm}$ continuous high power diode laser can be also used to pretreat the Co-cemented tungsten carbides prior to diamond deposition $[11,12]$. In order to prevent Co and $\mathrm{W}$ oxidation, the substrates can be placed in a protective chamber and flushed with pure $\mathrm{Ar}$ or $\mathrm{N}_{2}$ (99.999\%). A glass window at the top of the chamber allows delivery of laser irradiation and inspection. Laser power can be in the range of 500-1500 W, and scan speed is typically set at $1 \mathrm{~mm} / \mathrm{s}$ [11]. The beam is moved back and forth along linear and parallel patterns to uniformly cover the entire substrate surface with an overlap of $\sim 0.5-1.0 \mathrm{~mm}$ between two consecutive linear patterns. The total sample treatment can last up to $1 \mathrm{~min}$ [12].

\section{Experimental}

Selected case studies concerning the deposition of diamond coatings on Co-cemented tungsten carbides are hereby reported. The test cases deal with the different pretreatments, which can be used to favor the nucleation and growth of the diamond coatings and improve their adhesion to the substrate and the overall wear performance. The scenarios here investigated refer to the following class of pretreatments of the WC-Co substrates: (i) combined chemical etching and mechanical peening (i.e., fluidized bed treatment, FBT); (ii) application of a large variety of intermediate layers by PVD (intermediate layer treatment, ILT); (iii) thermal processing by $940 \mathrm{~nm}$ continuous high power diode laser (diode laser treatment, DLT). The pretreatments will be detailed in the incoming section.

The diamond coatings were always applied on $10 \times 10 \times$ 3 (ILT and DLT) or 4 (FBT) $\mathrm{mm}^{3}$ WC-5.8 wt.\%Co as-ground flat slabs, whose average grain size was $0.7-0.8$ (ILT and DLT) or 5-6 $\mu \mathrm{m}$ (FBT), Rockwell A hardness 90.0 HRA, and transverse rupture strength (TRS, according to ISO 3327) $2900 \mathrm{MPa}$. For comparative purposes, as-ground WC-Co substrates submitted to the well-known two-step chemical etching (Murakami's treatment) were also reported. During Murakami's treatment, the WC-Co substrate was first etched for $15 \mathrm{~min}$ with Murakami's reagent $\left(10 \mathrm{~g} \mathrm{~K}_{3}\left[\mathrm{Fe}(\mathrm{CN})_{6}\right]+\right.$ $10 \mathrm{~g} \mathrm{KOH}+100 \mathrm{~mL}$ of $\mathrm{H}_{2} \mathrm{O}$ ) to corrugate the WC grains.
Then, after rinsing in deionised water, the substrate was etched with Caro's acid ( $3 \mathrm{~mL} 96$ wt. $\% \mathrm{H}_{2} \mathrm{SO}_{4}+88 \mathrm{~mL} 30 \%$ (w/v) $\mathrm{H}_{2} \mathrm{O}_{2}$ ) for $10 \mathrm{~s}$ to wash surface Co out, and rinsed again in $\mathrm{H}_{2} \mathrm{O}$. After all the pretreatments except for FBT, the substrates were seeded in an ultrasonic bath with a slurry of diamond particles $(250 \mathrm{~nm}$ in diameter) in ethanol for $15 \mathrm{~min}$.

The deposition of diamond films was performed in a stainless steel HFCVD reactor. The gas phase, a mixture of hydrogen and methane with a $1 \% \mathrm{CH}_{4} / \mathrm{H}_{2}$ volume ratio, was activated by a set of linear tungsten filaments $(0.79 \mathrm{~mm}$ in diameter), whose temperature was kept at about $2500 \mathrm{~K}$ and monitored by a two-colour pyrometer (by IRCON). Total flow rate was 4000 standard $\mathrm{cm}^{3} \min ^{1}$ ( $\mathrm{sccm}$ ), and pressure was $10 \mathrm{kPa}$. Several samples were positioned on the substrate holder (a Mo grid) just below the filaments, being $12 \mathrm{~mm}$ the distance between the filament and the center of their top surface. The substrate temperature was $\sim 650^{\circ} \mathrm{C}$ and it was measured by placing a thermocouple in the bulk of a WC-Co substrate located under the filament. Deposition rates, under those CVD conditions, were $0.5-0.7 \mu \mathrm{m} / \mathrm{h}$, whilst deposition duration was varied from 3 to $15 \mathrm{~h}$.

Sample roughness before and after diamond deposition was measured by a contact gauge surface profiler (Taylor Hobson Surface Topography System Taly-Surf CLI 2000). 100 surface profiles with a lateral spacing of $10 \mu \mathrm{m}$ and with a resolution of $0.5 \mu \mathrm{m}$ were recorded. A very low scan speed of $50 \mu \mathrm{m} / \mathrm{s}$ was adjusted during the measurements in order to minimize the sliding speed of the stylus tip and ensure measurement accuracy. TalyMap software Release 3.1 was used for data analysis and image processing.

Field emission gun scanning electron microscopy (FEGSEM, LEO Supra 35) and energy dispersive X-ray spectroscopy (EDS, Oxford Instruments Ltd. Inca 300) were used to characterize the surface morphology after pre-treatments, CVD and wear tests, and to perform chemical analyses of the WC-Co substrates before and after each pre-treatment. Dry rotating and "linear reciprocating" tribological tests (Optimol SRV Tribometer) were performed in order to check wear resistance and film adhesion to differently pretreated WC-Co substrates. The samples were tested at $10 \mathrm{~N}$ in rotational mode (radius $3 \mathrm{~mm}$, frequency $10 \mathrm{~Hz}$, duration $60 \mathrm{~min}$, WC-5.8\%Co ball $6 \mathrm{~mm}$ diameter) and $60 \mathrm{~N}$ in backand-forth sliding (stroke length $2 \mathrm{~mm}$, frequency $50 \mathrm{~Hz}$, steel ball $10 \mathrm{~mm}$ diameter, duration $20 \mathrm{~min}$ ). Wear resistance of the coatings was assessed by contact gauge profiler. Volume, dimension and average depth of the wear tracks were obtained by using the features of the TalyMap software.

The adhesion of the diamond films was assessed by Brale indentation tests. The tests were performed using a Wolpert Rockwell hardness tester with a Brale diamond indenter having a cone of $120^{\circ}$ and a tip radius of $0.2 \mu \mathrm{m}$. According to Jindal et al. [30], when the applied load overcomes the so-called critical load, $P_{\text {cr }}$, the plastic deformation of the substrate induces the delamination of the film and cracks propagate between the film and the substrate. In this study, lateral crack diameter, $X$, was measured by SEM according to the procedure described in [31]. The results are plotted as a function of the loads, $P$, applied at the indenter tip. The 


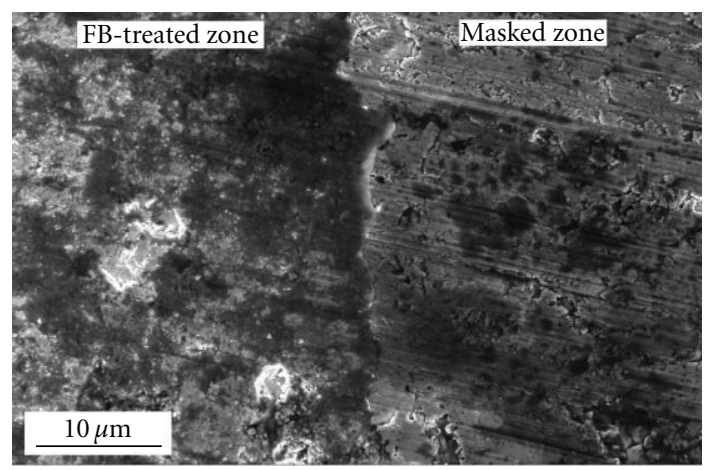

(a)

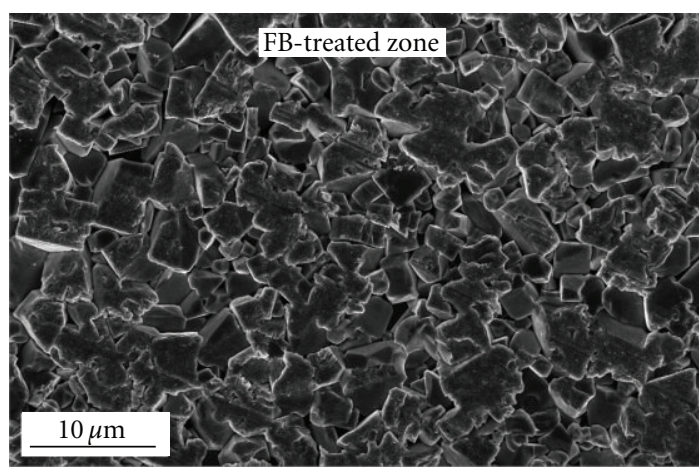

(b)

FIGURE 1: Morphology of WC-Co: (a) 16 h FB and masked; (b) FB after etching.

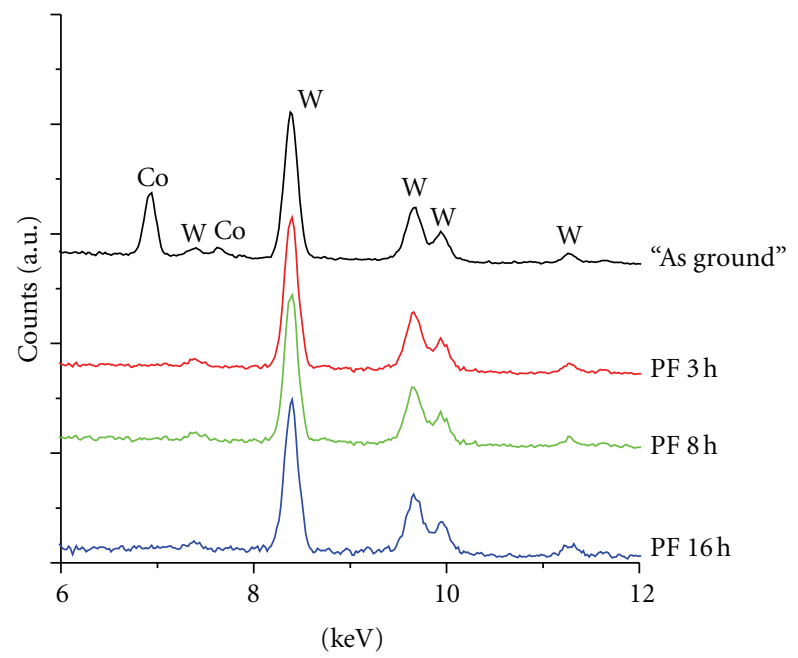

Figure 2: EDS after etching with Caro's acid and $3 \mathrm{~h}$ long FB treatment.

reciprocal of the slope obtained from the crack diameterindentation load plot, $(\mathrm{d} X / \mathrm{d} P)^{-1}$, was used as an estimation of the adhesion.

\section{Results and Discussion}

4.1. Mechanical Peening and Co Etching. A FB, $40 \times 40 \mathrm{~mm}^{2}$ cross-section and $100 \mathrm{~mm}$ static bed height, of diamond powder (120 mesh size, 0.67 factor shape), in fast regime (3.5-5 $\mathrm{m}^{3} / \mathrm{h}$ flow rate), was used to pretreat the WC-Co slabs. The slabs dipped in the fluidized powder were held on the shaft of a d.c. electrical motor and, rotated at moderate speed, they were exposed to the repeated impacts of incoming powders. Three slabs (namely., PF samples) were submitted to binder etching with Caro's acid (3 mL $96 \mathrm{wt} . \%$ $\mathrm{H}_{2} \mathrm{SO}_{4}+88 \mathrm{~mL} \mathrm{30 \%} \mathrm{w/v} \mathrm{H} \mathrm{O}_{2}$ ) for $10 \mathrm{~s}$ and to fluidized bed processing for 3, 8, or $16 \mathrm{~h}$. The fourth slab (viz., FP sample) was exposed to FB treatment prior to binder etching. Then, an etching with Caro's acid was performed. The fifth slab (MPS) was submitted to the Murakami's treatment [14].
Figure 1 shows the WC-Co substrate after $16 \mathrm{~h} \mathrm{FBT} \mathrm{and}$ after combined FBT and etching with Caro's acid. Significant changes in surface morphology can be noted with respect to as-ground substrate. Etching with Caro's acid removed surface Co, generating a slightly more roughened morphology $\left(S_{a}=0.14 \mu \mathrm{m}\right)$. When Co etching was performed prior to FBT, the surface binder removal led to the embrittlement of the WC-Co external layer. FB machining of such embrittled surfaces contributed to remove WC grains and to establish more corrugated morphology. The duration of the FBT significantly affected the final surface roughness of PF samples. In fact, $S_{a}$ of $0.17 \mu \mathrm{m}, 0.25 \mu \mathrm{m}$, and $0.27 \mu \mathrm{m}$ were measured for samples submitted to 3,8 , and $16 \mathrm{~h}$ FBT, respectively. This was because longer FBT had much more time to complete the removal of embrittled external layers of carbide grains, thereby establishing a rougher surface morphology. Figure 2 shows the EDS spectra of as-ground WC-Co and of substrates submitted to etching with Caro's acid and FBT for 3, 8 and $16 \mathrm{~h}$. Binder concentration was below the detection limit. Figure 3 reports the diamond films. The morphology of coated samples becomes progressively rougher according to the FBT time. Spatial roughness $S_{a}$ varied from $0.19 \mu \mathrm{m}$ for PF sample $3 \mathrm{~h} \mathrm{FBT} \mathrm{to} 0.25$ and $0.26 \mu \mathrm{m}$, respectively, for $\mathrm{PF}$ samples $8 \mathrm{~h}$ and $16 \mathrm{~h}$ FBT. An even rougher diamond film was achieved on MPS sample $\left(S_{a}=0.35 \mu \mathrm{m}\right)$. FBT allowed attaining diamond coatings with finer grain size. Being the grains size related to nucleation density according to the model of "evolutionary selection" [32], FBT caused an enhancement of diamond nucleation density. Such effect can be ascribed to defects at the WC-Co surface induced by the grinding and FBT. Indentation tests confirmed that all diamond films were well adhered, with no noteworthy differences in film adhesion arising. Figure 4 shows the results in terms of crack radius versus indentation load. The $(\mathrm{d} X / \mathrm{d} P)^{-1}$ parameter averaged on PF-pretreated WCCo substrates was around $0.216 \pm 0.03 \mathrm{~kg} / \mu \mathrm{m}$ and very close to the value of $0.213 \mathrm{~kg} / \mu \mathrm{m}$ achieved on MPS.

4.2. Interlayers. Interlayers consisting of $\mathrm{TiN}, \mathrm{TiC}, \mathrm{Ti}(\mathrm{C}$, $\mathrm{N})$, CrN, or CrC were deposited by PVD-arc technology on the WC-Co flat slabs. In Table 1 the thickness of 

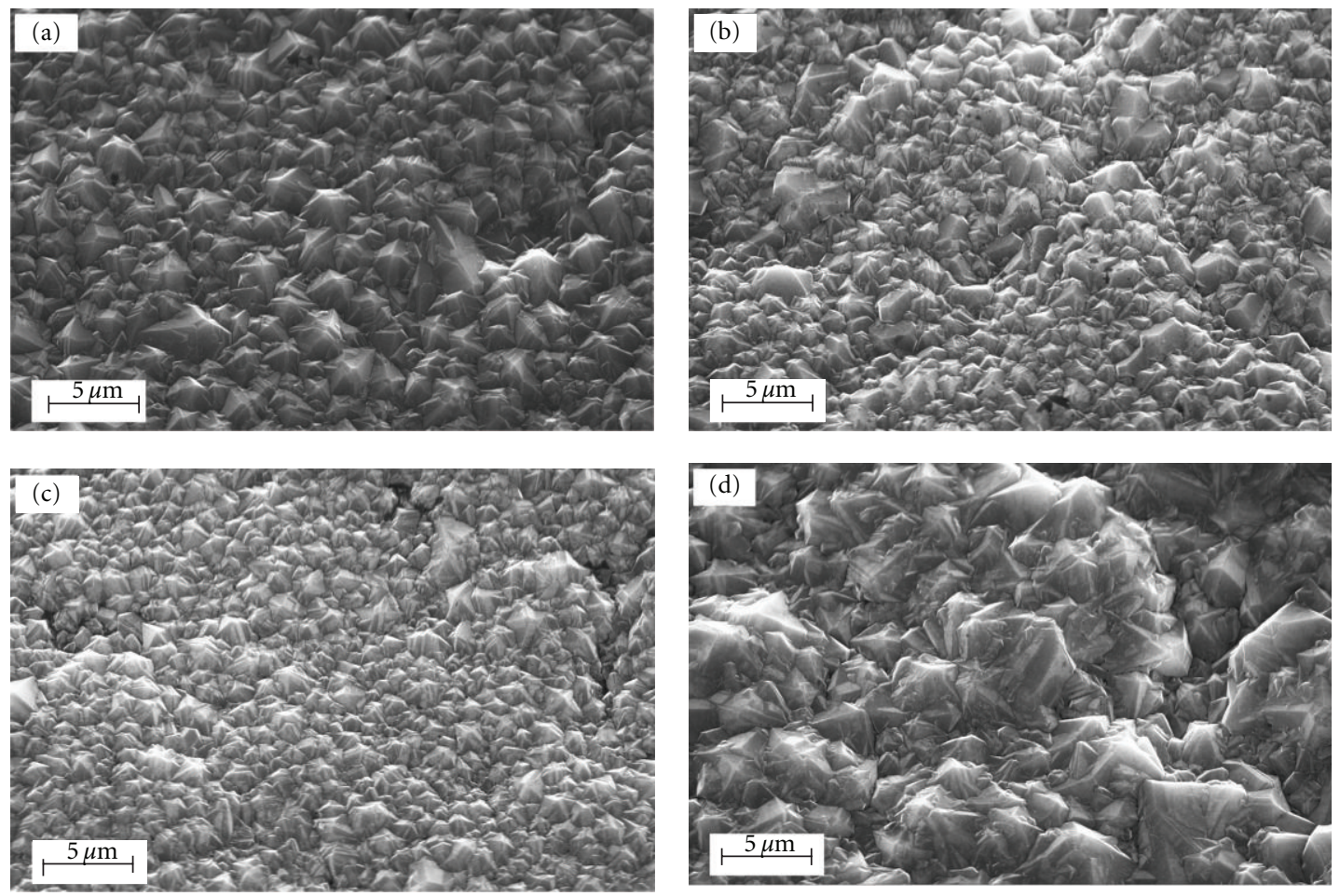

Figure 3: Diamond films after 8 h HF-CVD (a), PF 16 (b), PF 8 (c), and PF 3 (d) MPS.

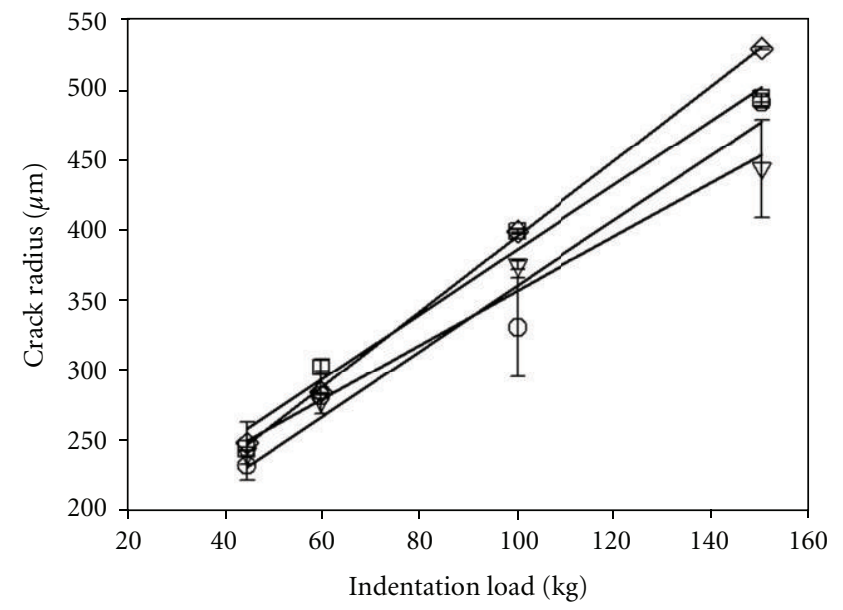
O MPS
$\square$ PF $8 \mathrm{~h}$
$\nabla$ PF $3 h$
$\diamond \mathrm{PF} 16 \mathrm{~h}$

FIGURE 4: Crack radius versus indentation load function.

the PVD coatings, gas phase composition, and deposition temperatures are summarized.

Figure 5 shows the surface morphology of arc-evaporated interlayers. All PVD films showed the presence of globules (or "macros"). During cathode evaporation, the vacuum arc discharge ejects microscopic droplets from the cathode towards the substrates which cause a roughness increase on the coated parts [33]. Both size distribution function and surface density of droplets incorporated into the growing film depend, under given process conditions, on deposition time, and, therefore, on film thickness. SEM micrographs show that larger macroparticles are formed at the surface of thicker TiN films (sample TiN_a, Figure 5(a)) with respect to both thinner TiN films (TiN_b, Figure 5(b)), which were obtained by multiple rotation of the substrates during PVD, and 3- $\mu \mathrm{m}$ thick Ti(C, N) coatings (Figure 5(d)). Figure 5 (c) shows the morphology of $2-\mu \mathrm{m}$ thick TiC coatings. TiC coating exhibited a larger macroparticles density than TiN_b films with comparable thickness. CrN interlayers (Figure 5(e)) exhibited smaller droplets than TiN coatings with comparable thickness (Figure 5(a)), and thin $(0.6 \mu \mathrm{m})$ $\mathrm{CrC}$ films were very smooth, being the surface morphology identical to that of as-ground WC-Co substrates.

Figure 6 shows the SEM micrographs of diamond coatings deposited onto different interlayers. A continuous diamond film was obtained after $3 \mathrm{~h}$ deposition. In the case of TiN_b interlayered sample, the diamond film underwent spontaneous delamination on cooling from deposition temperature to room temperature. After $3 \mathrm{~h}$ growth process, the surface morphology of the substrates was not significantly modified by the presence of the thin $(\sim 2 \mu \mathrm{m})$ diamond film. In fact, diamond coated macros were clearly visible at the surface of WC-Co substrates with Ti-based interlayers (Figures 6(a)-6(c)). The smooth surface morphology of the thin CrC interlayer was maintained after $3 \mathrm{~h} \mathrm{CVD}$ (Figure 6(d)). Figures 6(e) and 6(f) show the morphology of the coating after $3 \mathrm{~h}$ and $9 \mathrm{~h} C V D$, respectively. After $9 \mathrm{~h}$ deposition and consequently to the increase of film thickness, macros were embedded in the diamond coating, thus, allowing to obtain a smoother surface of the sample. 

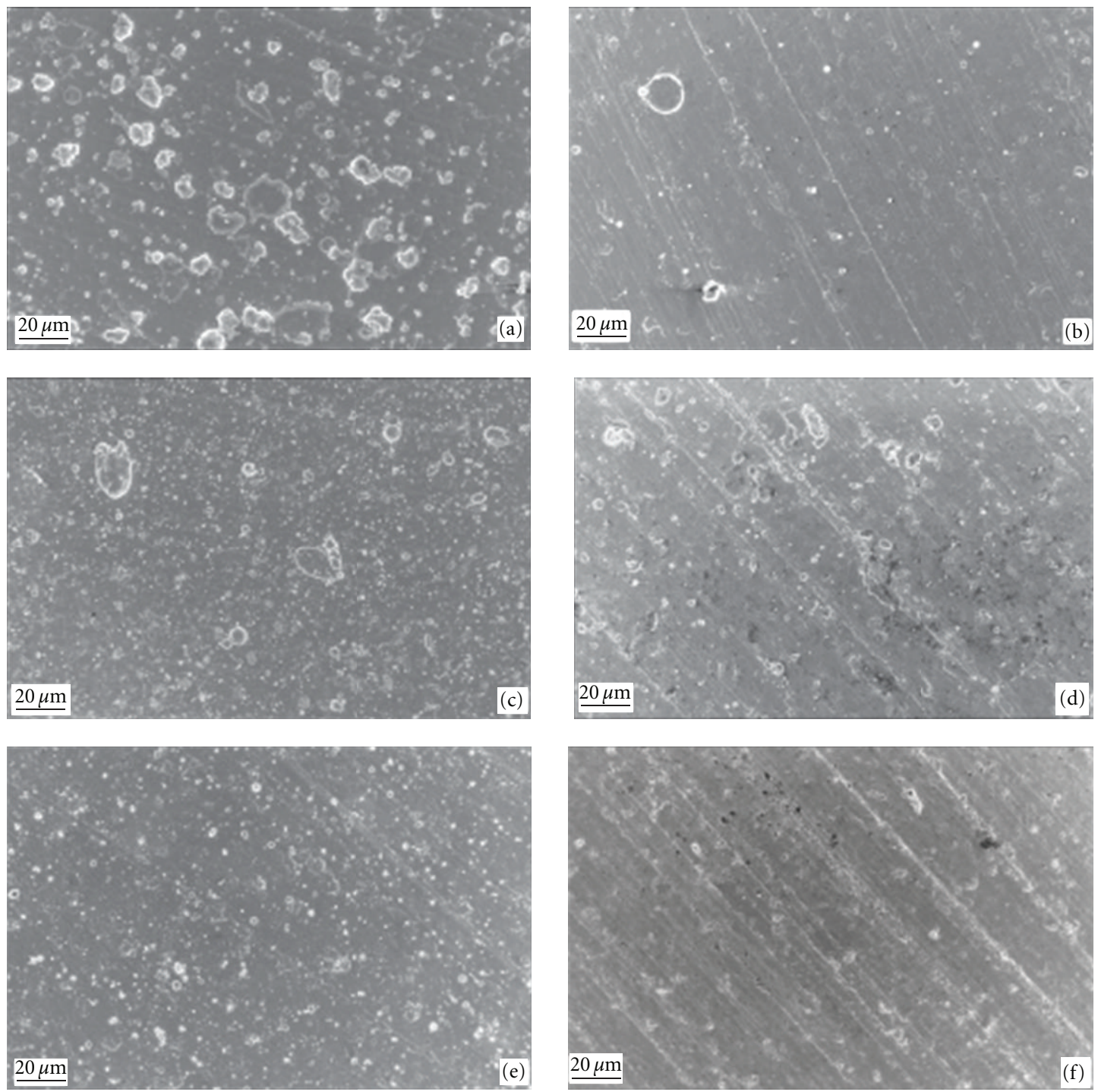

Figure 5: Surface morphology of arc-evaporated interlayers: (a) TiN_a, (b) TiN_b, (c) TiC, (d) Ti(C, N), (e) CrN, and (f) CrC.

TABLE 1: PVD parameters and thickness of arc evaporated Cr- and Ti-based interlayers.

\begin{tabular}{lccccccc}
\hline Interlayer & Bias $(\mathrm{V})$ & \multicolumn{3}{c}{ Gas phase } & Chamber pressure $(\mathrm{Pa})$ & Deposition temperature $\left({ }^{\circ} \mathrm{C}\right)$ & Thickness $(\mu \mathrm{m})$ \\
\hline CrN & -80 & - & $100 \%$ & - & 2.0 & 350 & 8 \\
TiN_a & -135 & - & $100 \%$ & - & 1.5 & 450 & 4 \\
TiN_b & -135 & - & $100 \%$ & - & 1.5 & 450 & 3.3 \\
CrC & -70 & $84 \%$ & - & $16 \%$ & 1.0 & 450 & 0.6 \\
TiC & -70 & $70 \%$ & - & $30 \%$ & 1.0 & 450 & 2 \\
Ti $(\mathrm{C}, \mathrm{N})$ & -70 & - & $84 \%$ & $16 \%$ & 1.0 & $\mathrm{CH}_{4}$ & \\
\hline
\end{tabular}

Figure 7 shows the groove morphology obtained for the uncoated, PVD-coated, and HF-CVD-coated specimens after 30 min dry sliding wear tests. Figure 8 shows the volume losses as determined by three-dimension profilometry. The volume losses of samples submitted to $3 \mathrm{~h}$ CVD were systematically less than the ones measured on PVD-coated substrates. Only $\mathrm{Ti}(\mathrm{C}, \mathrm{N})$ samples showed comparable wear.
The presence of macros, although was deleterious for getting high levels of wear resistance, played some positive effect on the adhesion of diamond films. In fact, the adhesion of diamond on the smooth TiN_b substrate was practically nil, while the diamond-coated TiN_a sample showed a better wear resistance (wear volume $=4.2 \cdot 10^{5} \mu \mathrm{m}^{3}$ ) compared to bare WC-Co $\left(\right.$ wear volume $\left.=1.6 \cdot 10^{6} \mu \mathrm{m}^{3}\right)$. The overall 


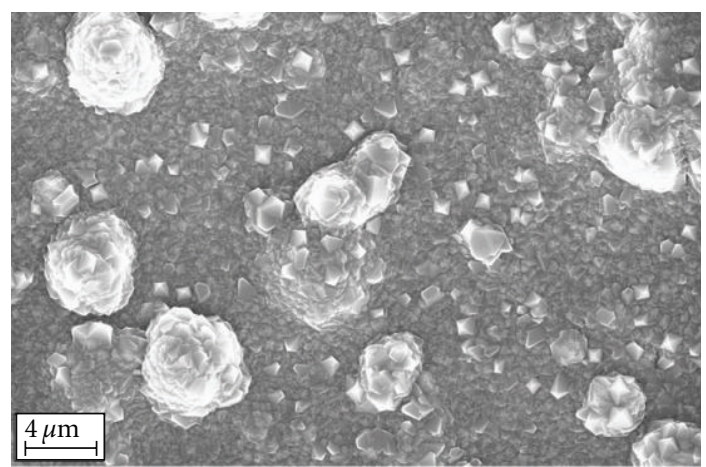

(a)

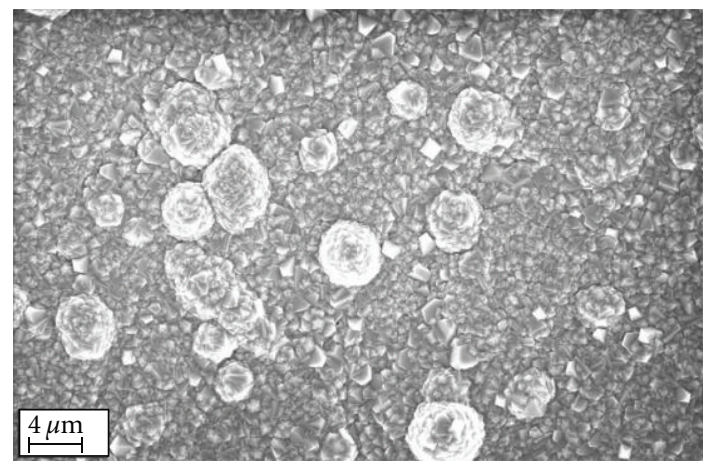

(c)

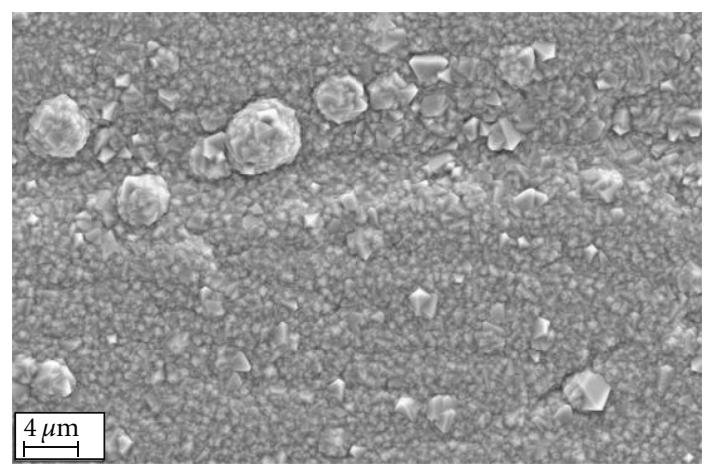

(e)

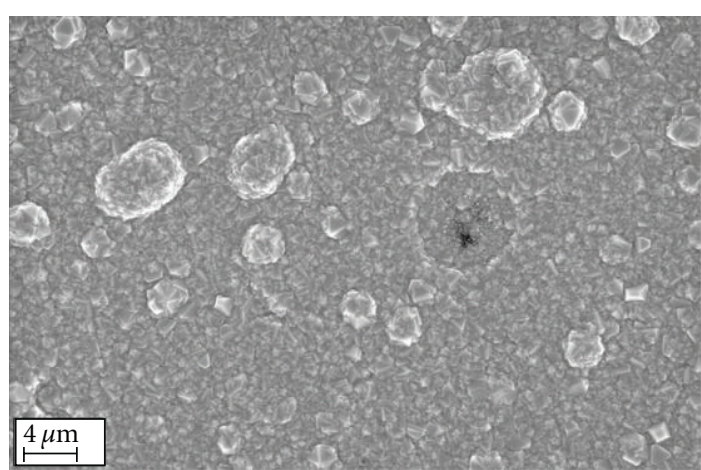

(b)

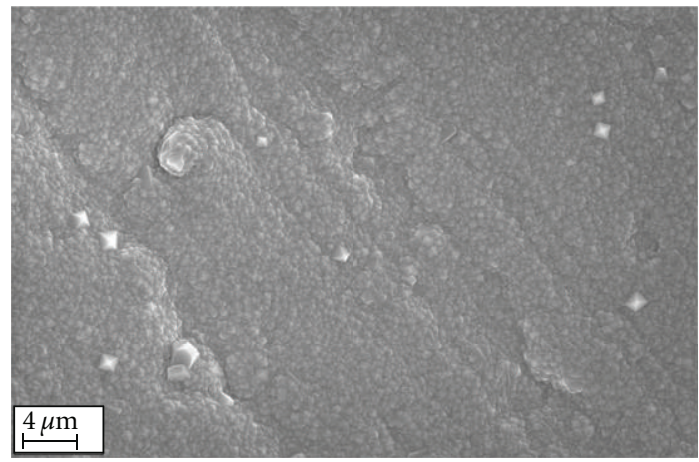

(d)

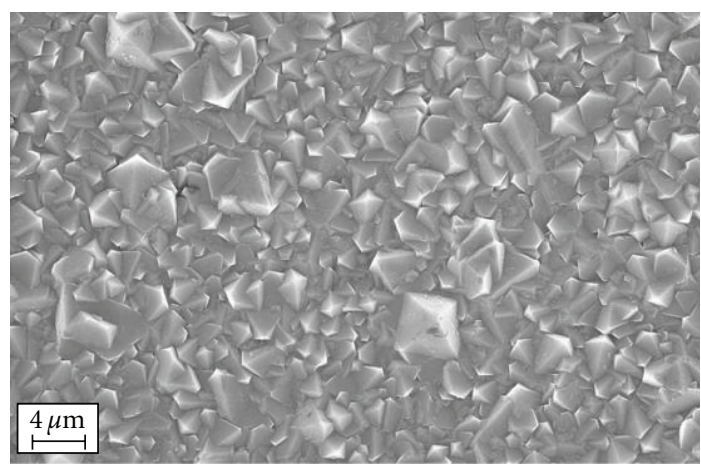

(f)

FIGURE 6: SEM micrographs of diamond films grown by HFCVD on different interlayered WC-Co samples: (a) $3 \mathrm{~h}$ CVD on TiN_a, (b) $3 \mathrm{~h}$ CVD on TiC, (c) 3 h CVD on Ti(C, N), (d) 3 h CVD on CrC, (e) 3 h CVD on CrN, and (f) 9 h CVD on CrN.

results indicate that the chemical bonds between diamond and TiN were not strong enough, and that the satisfactory adhesion level in the case of TiN_a sample was mostly attributable to the three-dimensional (3D) interface, which is expected to increase, according to Singh et al. [8], the adhesive strength by modifying the stress distribution in the diamond coating. In the case of the $\mathrm{CrC}$ interlayer, the good adhesion has to be ascribed to stronger chemical bonds between the diamond film and chromium carbides, rather than to interface morphology issues. The role of surface morphology of the diamond-coated sample on wear behaviour was demonstrated in the case of $\mathrm{CrN}$-interlayered substrates. In fact, the wear volume of the sample coated with $9 \mathrm{~h}$ CVD diamond was practically nil. This fact was attributable to the more regular surface morphology of the thicker diamond coating, where most macros were completely embedded (Figure 5(f)). Therefore, the surface roughness was determined by the faceted morphology of diamond crystallites, and no removal of macros and consequent local damage could occur during the sliding test.

4.3. Laser Treatments. WC-Co slabs were treated by a $940 \mathrm{~nm}$ continuous wave high-power diode laser (cw-HPDL) in a protective environment (Ar) to prevent $\mathrm{Co}$ and $\mathrm{W}$ oxidation. Laser power was varied in the range of 600 to $1500 \mathrm{~W}$, and scan speed was set at $1 \mathrm{~mm} / \mathrm{s}$. Laser beam was focused (elliptical spot size $3.8 \times 1.2 \mathrm{~mm}$ ) on the sample and, then, moved back and forth along three linear and parallel patterns 


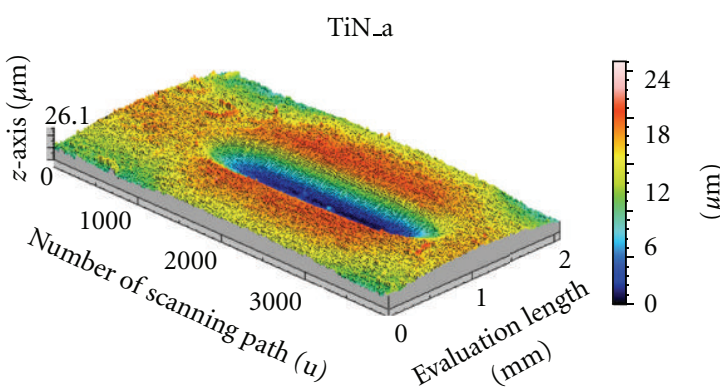

(a)

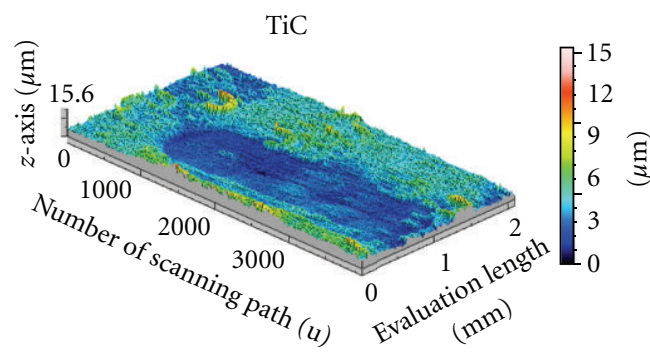

(c)

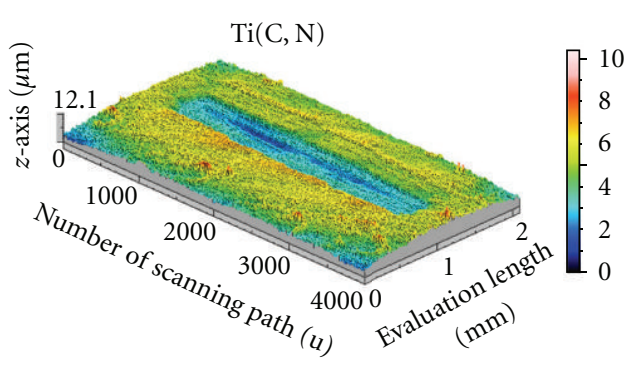

(e)

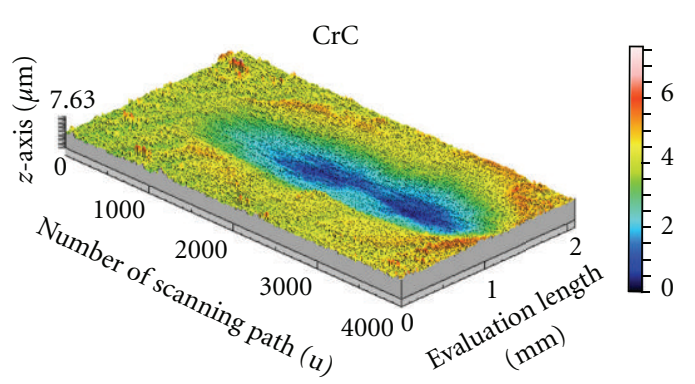

(g)

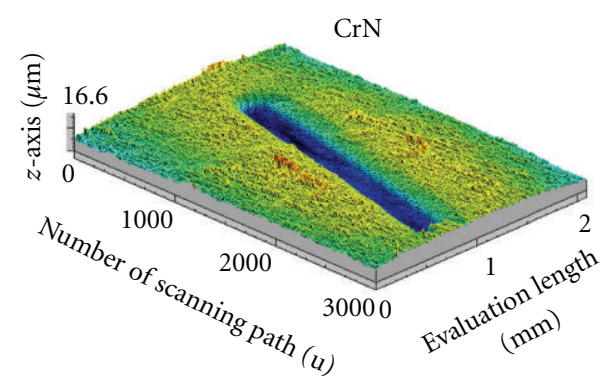

(i)

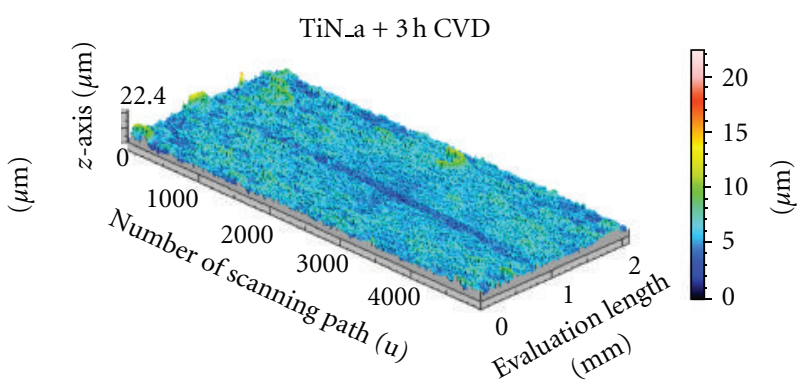

(b)

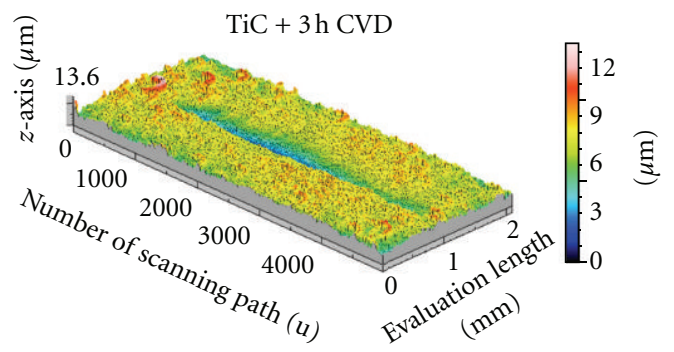

(d)

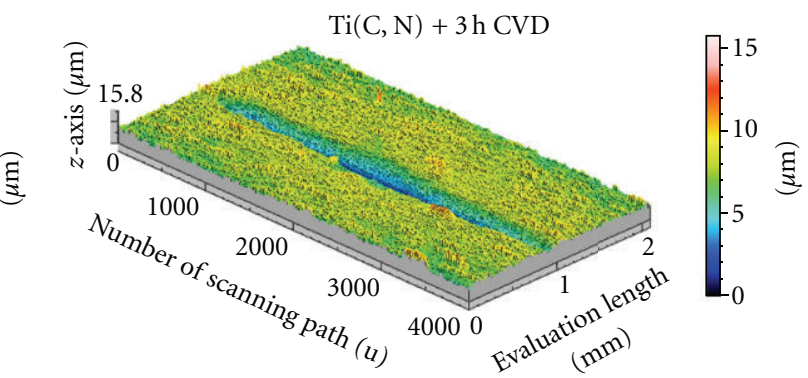

(f)

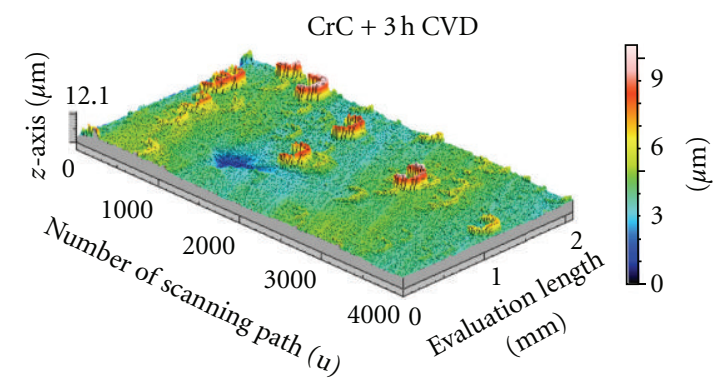

(h)

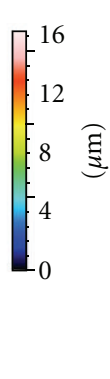

${ }_{4}^{12}$

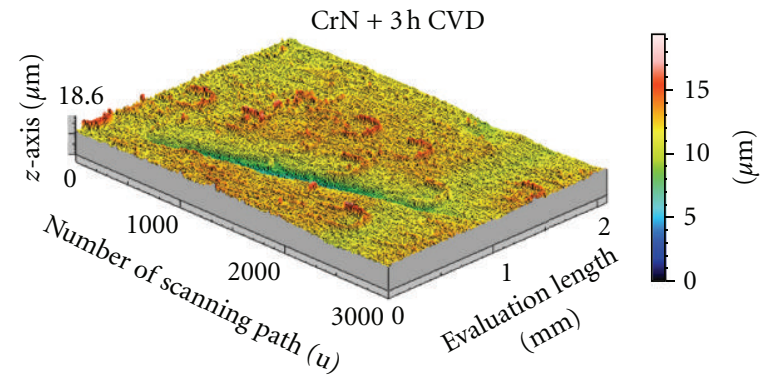

(j)

FIgURe 7: Continued. 


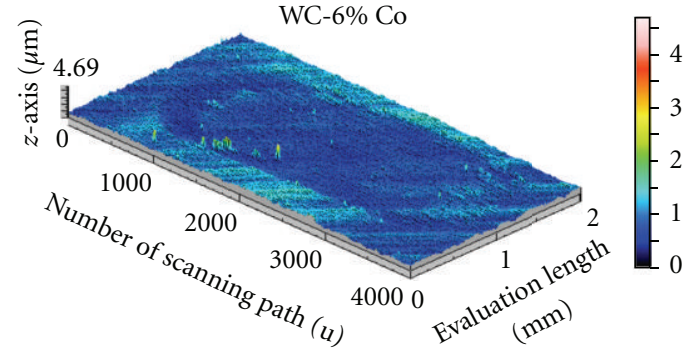

$(\mathrm{k})$

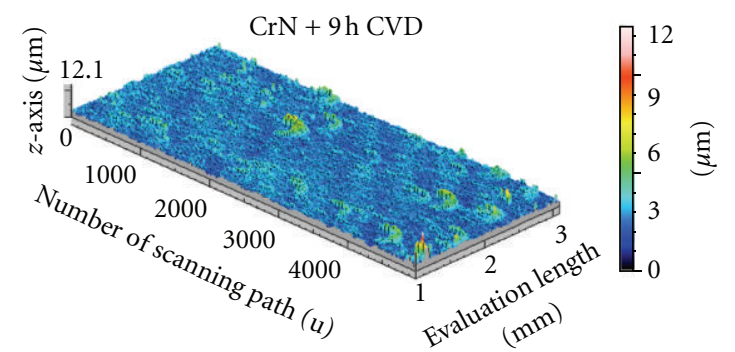

(1)

Figure 7: Wear tracks of uncoated, PVD- and CVD-coated samples.

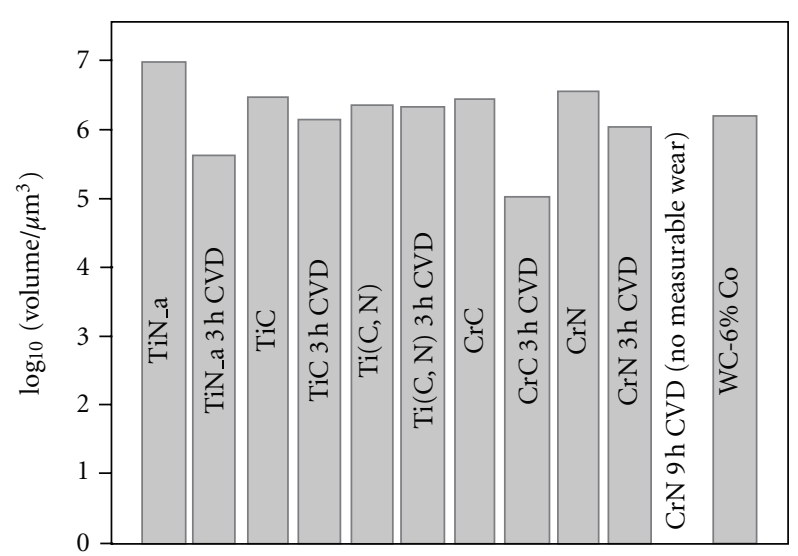

Figure 8: Wear volume of different samples submitted to dry sliding.

up to uniformly cover the entire substrate surface with an overlap of $0.7 \mathrm{~mm}$ among the different laser passes. Asground WC-Co submitted to two-step chemical etching (MP treatment) were also investigated.

Figure 9 reports the evolution of the WC-Co morphology by varying the laser power from 600 to $1500 \mathrm{~W}$. Figure 9(a) shows the starting morphology of the as-received WC-Co. WC grains are not clearly distinguishable, and Co matrix is spread over the surface. The morphology is also characterized by several macrostripes spreading over the surface as a result of the previous grinding process. Laser processing modifies the morphology of the WC-Co (Figures 9(b)-9(i)). Basically, laser selectively removes Co and allows WC grains sticking out from the "bulk" of the substrate. Such effect is even more apparent at any time laser power is increased (Figures 9(e)-9(i)). Co binder is reduced at the outermost layer of the WC-Co. The starting surface texture of the asground surface is not visible anymore, and the individual WC grains protrude from the core of the material. Increasing the power causes the increase in the average size of the WC grains and this contributes to the establishment of a rougher profile on the WC-Co. EDS analysis of the WC-Co after laser and MP treatments is reported in Figure 10. Increasing laser power from 800 to $1500 \mathrm{~W}$, Co is progressively reduced up to nearly completely disappear. Similarly, Co after MP treatments is nearly completely disappeared. MP and some laser-treated samples can be therefore submitted to diamond CVD without any further treatment.

Figure 11 reports the morphology of the diamond coating deposited on MP-and laser- $(1250 \mathrm{~W})$ treated WCCo substrate. It can be argued that after laser treatment the resulting diamond coating presents the same morphological characteristic of the coating deposited after the state-of-art MP treatment. Under both circumstances, small diamond crystallites due to secondary nucleation grow onto largesized crystallites.

Both diamond films are continuous and uniformly cover the underlying WC-Co substrates. Wear resistance and adhesion of diamond films deposited on MP-and lasertreated WC-Co substrates were comparatively evaluated, too.

Figure 12 and Table 2 summarize the wear performance of the diamond films deposited by $10 \mathrm{~h} \mathrm{CVD}$ onto the laser and MP-treated WC-Co substrates. The circular wear pattern was chosen to allow checking wear endurance of the diamond films by continuously varying the direction of the counterpart, being the laser treatment unidirectional. Diamond films on laser-treated substrates behave better at any time laser power is increased. The diamond films deposited on WC-Co treated at laser power of $1200 \mathrm{~W}$ or lower are characterized by the presence of uneven wear patterns, with the occurrence of some delamination phenomena of progressively bigger extent when lower laser power is set (Figures 12(a)-12(e)).

Table 2 shows that the size of the wear patterns due to delamination is progressively decreasing when laser power is increased from 800 to $1200 \mathrm{~W}$ (worn volume from $\sim 0.0582$ to $0.0019 \mathrm{~mm}^{3}$, worn surface from $\sim 21.6$ to $0.0179 \mathrm{~mm}^{2}$ ). However, the diamond film is mostly locally affected, with partial delamination occurring and not spreading too much in the surroundings. The diamond films deposited on the WC-Co laser treated at $1300 \mathrm{~W}$ and over are characterized by the lack of any visible wear damage (Figure 12(f)). Such better behaviour can be ascribed to the better removal of Co and the increase in the contact surface between the diamond and the underlying substrate itself. As seen before, laser treatments at high power tend to corrugate the WCCo substrates and promote a better adhesion with the overlying diamond coating by mechanical interlocking. Wear performance of WC-Co after proper laser and MP treatments are comparable, too. In fact, even the diamond film deposited 


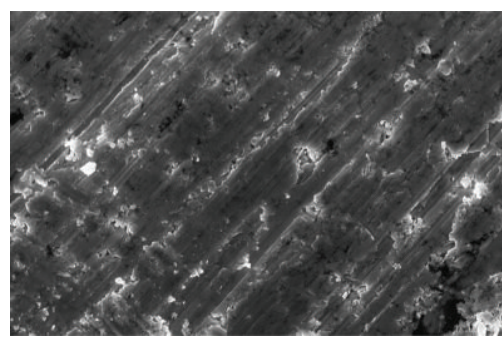

(a)

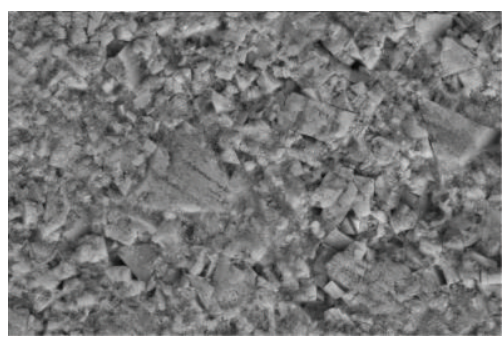

(d)

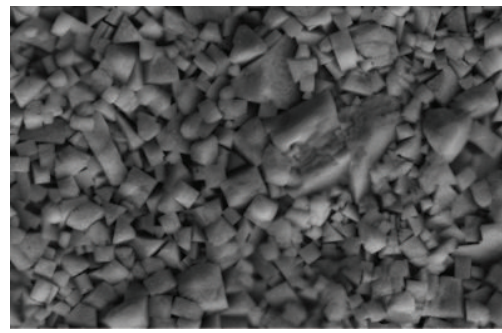

(g)

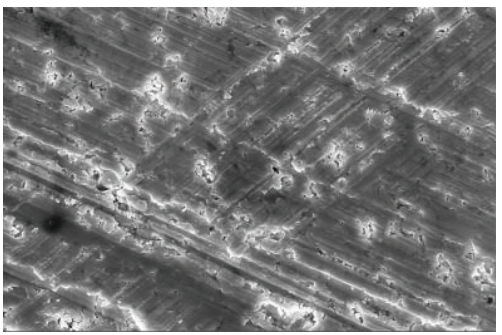

(b)

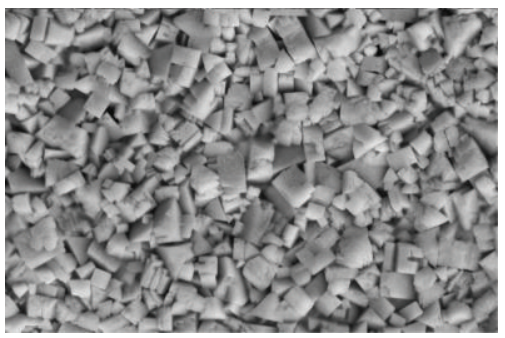

(e)

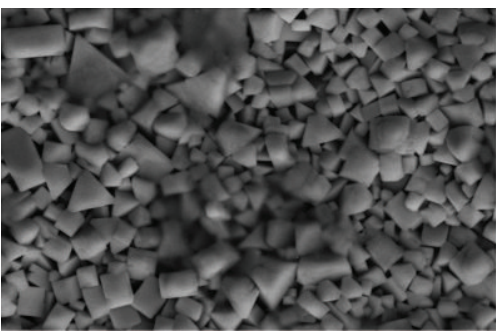

(h)

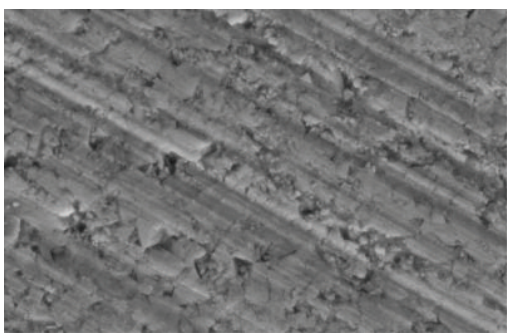

(c)

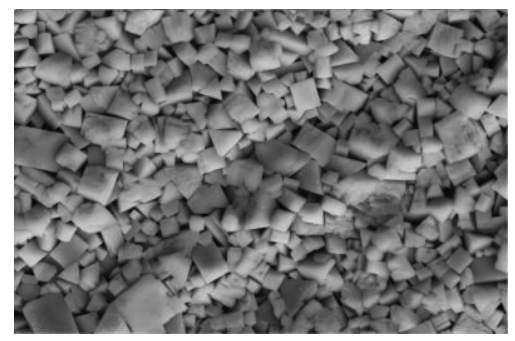

(f)

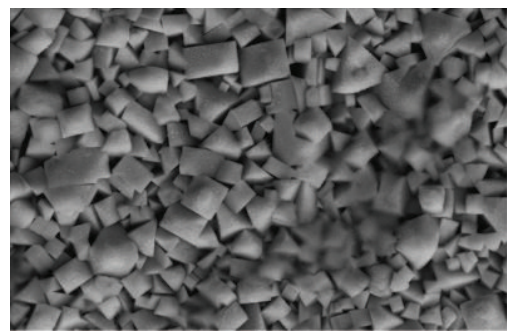

(i)

\section{$5 \mu \mathrm{m}$}

FIGURE 9: WC-Co substrate after and before laser processing: (a) as-received, (b) $600 \mathrm{~W}$, (c) $800 \mathrm{~W}$, (d) $900 \mathrm{~W}$, (e) $1000 \mathrm{~W}$, (f) $1100 \mathrm{~W}$, (g) $1200 \mathrm{~W}$, (h) $1300 \mathrm{~W}$,(i) $1400 \mathrm{~W}$.

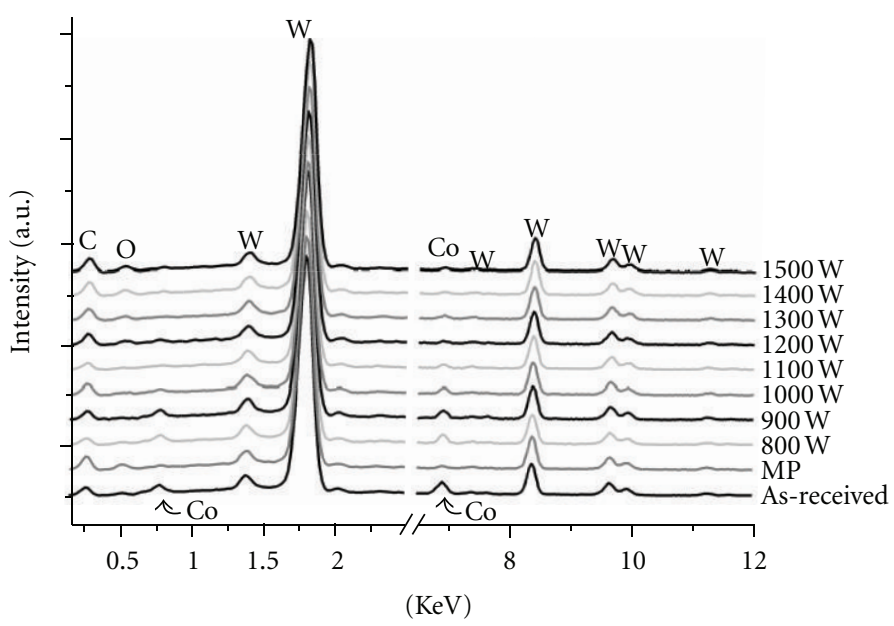

FIGURE 10: EDS of as-received, MP-treated and laser-treated WC-Co substrates.

on WC-Co after MP treatment withstands the tribological test, without any occurrence of delamination phenomena (Table 2).

In order to rank the performance of diamond films deposited onto laser $(1250 \mathrm{~W})$ and MP-treated WC-Co substrate, indentation tests with progressively increasing loads were performed, too. The experimental findings show that both diamond films were characterized by a good adhesion to the substrate, with no noteworthy differences regardless the applied load. 


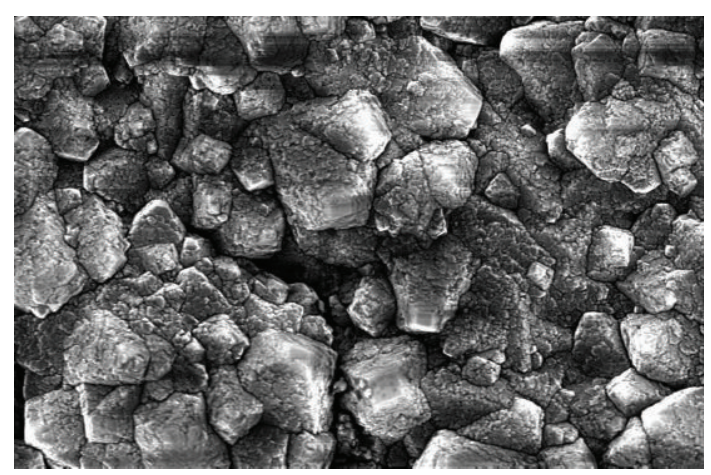

(a)

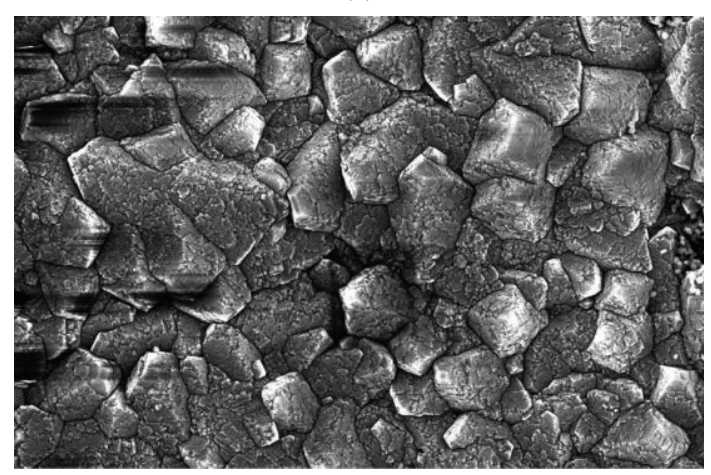

(b)

$1 \mu \mathrm{m}$

FIGURE 11: SEM morphology of diamond-coated WC-Co substrate after MP and $1250 \mathrm{~W}$ laser processing.

TABLE 2: Wear resistance of the diamond coatings after laser and MP treatments.

\begin{tabular}{lcccc}
\hline Sample & Worn surface, $\mathrm{mm}^{2}$ & Worn volume, $\mathrm{mm}^{3}$ & Max depth, $\mu \mathrm{m}$ & Mean depth, $\mu \mathrm{m}$ \\
\hline $800 \mathrm{~W}$ & 21.6 & 0.0582 & 12.5 & 2.69 \\
$900 \mathrm{~W}$ & 14.7 & 0.0342 & 11.8 & 2.32 \\
$1000 \mathrm{~W}$ & 1.32 & 0.0185 & 5.77 & 1.4 \\
$1100 \mathrm{~W}$ & 0.0181 & 5.83 & 1.4 \\
$1200 \mathrm{~W}$ & 1.29 & 0.0019 & 4.64 & 1.08 \\
$1300 \mathrm{~W}$ & 0.179 & 0 & 0 & 0 \\
$1400 \mathrm{~W}$ & 0 & 0 & 0 & 0 \\
$1500 \mathrm{~W}$ & 0 & 0 & 0 & 0 \\
MP & 0 & 0 & 0 & 0 \\
\hline
\end{tabular}

TABLE 3: Cracks radius on diamond coatings after laser $(1250 \mathrm{~W})$ and MP treatments.

\begin{tabular}{lcc}
\hline \multirow{2}{*}{ Load } & \multicolumn{2}{c}{ Crack radius, $\mu \mathrm{m}$} \\
& After laser treatment at $1250 \mathrm{~W}$ & After MP treatment \\
\hline $28 \mathrm{~kg}$ & $195 \pm 23$ & $204 \pm 29$ \\
$45 \mathrm{~kg}$ & $253 \pm 31$ & $239 \pm 28$ \\
$62 \mathrm{~kg}$ & $290 \pm 30$ & $308 \pm 36$ \\
$105 \mathrm{~kg}$ & $388 \pm 59$ & $370 \pm 38$ \\
$154 \mathrm{~kg}$ & $483 \pm 41$ & $495 \pm 46$ \\
\hline \multicolumn{3}{c}{$(\mathrm{d} X / \mathrm{d} P)^{-1}, \mu \mathrm{m} / \mathrm{kg}$} \\
\hline
\end{tabular}

Table 3 reports the experimental data in terms of crack radius versus indentation load. Average $(\mathrm{d} X / \mathrm{d} P)^{-1}$ parameter measured on diamond deposited on laser-treated WC-Co substrate was $\sim 0.437 \pm 0.03 \mathrm{~kg} / \mu \mathrm{m}$ and very close to the value of $0.452 \pm 0.03 \mathrm{~kg} / \mu \mathrm{m}$ achieved on diamond deposited on MP-treated WC-Co substrate. Such results are in accordance with results measured for films of similar thickness and grown onto MP-treated WC-Co substrate [34, 35]. Laser treatments of WC-Co can be therefore as effective as the widely recognized Murakami's treatment insofar as the adhesion of diamond coatings on WC-Co substrates is concerned. These findings also agree with several data reported in the relevant literature, that is, that proper 

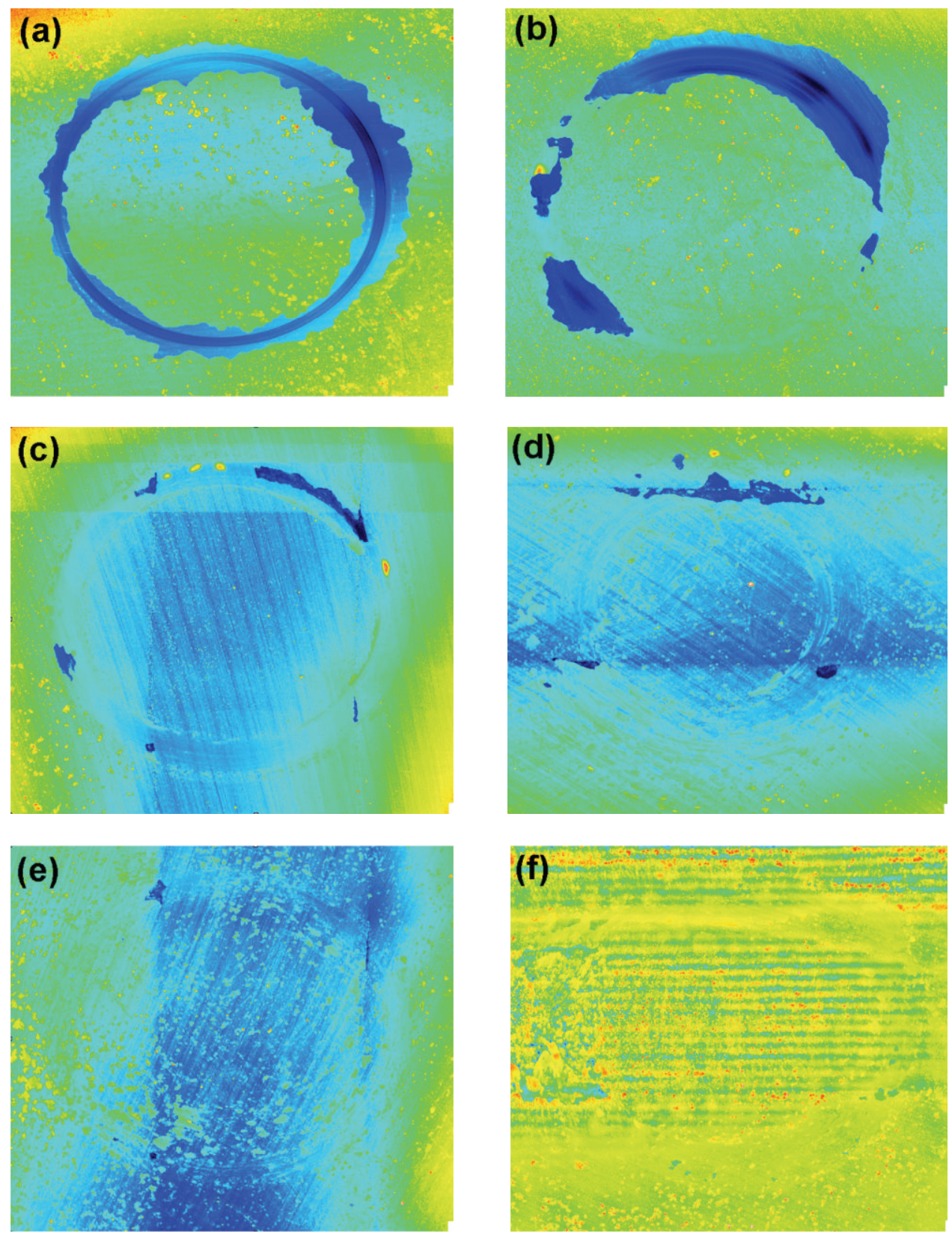

$3 \mathrm{~mm}$

Figure 12: Wear patterns of diamond coated WC-Co substrate: (a) $800 \mathrm{~W}$, (b) $900 \mathrm{~W}$, (c) $1000 \mathrm{~W}$, (d) $1100 \mathrm{~W}$, (e) $1200 \mathrm{~W}$, (f) $1300 \mathrm{~W}$.

substrate surface roughening is a crucial issue affecting diamond film adhesion $[8,34,35]$.

\section{Conclusions}

Some conclusions can be drawn as following.

(1) FB treatment after chemical etching with Caro's reagent caused (i) a perceptible modification of the surface morphology of the substrate with the $16 \mathrm{~h}$ long FB-pretreatment producing the more roughened WC-Co substrate, (ii) to deposit by HFCVD a continuous and well-adhered diamond film all over the substrates with a very high nucleation density without any further nucleation enhancement pretreatment, and, (iii) consequently, to obtain smooth and fine-grained polycrystalline diamond coatings. If the FB treatment of hardmetal substrates was performed prior to binder etching, that is, directly on as-ground WC-Co substrates, a smoother surface morphology was attained. Rockwell indentation tests showed that the adhesion of diamond films deposited on FB-pretreated substrates was as good as the one obtained for Murakami pre-treated substrates. 
(2) The interlayer surface morphology played an important role in determining the performance of thin diamond films. Good wear resistance was exhibited by $\mathrm{TiN}$ and $\mathrm{TiC}$ interlayers characterized by large macros, whereas the adhesion of diamond on smooth TiN interlayers was very low. The wear resistance of diamond films on $\operatorname{Ti}(\mathrm{C}, \mathrm{N})$ interlayered sample was poor, independently of the diamond film thickness. Better results were obtained in the case of Cr-based interlayers. The sample obtained by combining a thin $\mathrm{CrC}$ interlayer with a thin diamond film exhibited a wear volume about one order of magnitude less than bare WC-Co substrate. The use of $\mathrm{CrN}$ also proved to be effective in enhancing the properties of diamond films. In fact, diamond coatings thick enough to completely surround $\mathrm{CrN}$ globules, showed an excellent behaviour with no measurable wear volume after 30 min dry sliding against steel counterface. The good adhesion between diamond and Cr-based interlayers might be ascribed to the interfacial formation of crystalline chromium carbides during HFCVD.

(3) High power diode laser allows the selective removal of Co from the outermost layer of the WC-Co, leaving substantially unchanged the configuration and microstructure of the WC grains. The achieved morphology and the elementary chemical composition of the outermost layer of the laser-treated materials is very close to those achievable by the state-of-art of chemical treatment of the WC-Co substrate, that is, the MP treatment. The main mechanism by which the "low melting and boiling point" Co is selectively removed is by local melting and vaporization in the surrounding of the hotter "high melting and boiling point" WC. In fact, WC grains can reach higher temperature under laser source, being better energy absorber in NIR region and possessing lower thermal conductivity and high thermal capability than Co. A fluence of $134 \mathrm{~J} / \mathrm{mm}^{2}$ can be considered the threshold to significantly activate the removal of Co, whilst a fluence of $218 \mathrm{~J} / \mathrm{mm}^{2}$ is enough to activate first modification of the WC grains by melting and resolidification in the form of larger agglomerate. Fluence in excess of $250 \mathrm{~J} / \mathrm{mm}^{2}$ initiates a sort of WCCo surface reconstruction, with significant melting and resolidification phenomena. In that case, Co cannot be selectively removed without affecting the structure of the WC.

\section{References}

[1] X. Chen and J. Narayan, "Effect of the chemical nature of transition-metal substrates on chemical-vapor deposition of diamond," Journal of Applied Physics, vol. 74, no. 6, pp. 41684173, 1993.

[2] K. Shibuki, M. Yagi, K. Saijo, and S. Takatsu, "Adhesion strength of diamond films on cemented carbide substrates," Surface and Coatings Technology, vol. 36, no. 1-2, pp. 295-302, 1988.
[3] J. Oakes, X. X. Pan, R. Haubner, and B. Lux, "Chemical vapour deposition diamond coatings on cemented carbide tools," Surface and Coatings Technology, vol. 47, no. 1-3, pp. 600-607, 1991.

[4] I. Y. Konyashin and M. B. Guseva, "Thin films comparable with WC-Co cemented carbides as underlayers for hard and superhard coatings: the state of the art," Diamond and Related Materials, vol. 5, no. 3-5, pp. 575-579, 1996.

[5] I. Endler, A. Leonhardt, H. J. Scheibe, and R. Born, "Interlayers for diamond deposition on tool materials," Diamond and Related Materials, vol. 5, no. 3-5, pp. 299-303, 1996.

[6] X. Xiao, B. W. Sheldon, E. Konca, L. C. Lev, and M. J. Lukitsch, "The failure mechanism of chromium as the interlayer to enhance the adhesion of nanocrystalline diamond coatings on cemented carbide," Diamond and Related Materials, vol. 18, no. 9, pp. 1114-1117, 2009.

[7] K. Saijo, M. Yagi, K. Shibuki, and S. Takatsu, "Improvements in adhesive strength and cutting performance of diamondcoated tools," Surface and Coatings Technology, vol. 47, no. 1-3, pp. 646-653, 1991.

[8] R. K. Singh, D. R. Gilbert, J. Fitz-Gerald, S. Harkness, and D. G. Lee, "Engineered interfaces for adherent diamond coatings on large thermal-expansion coefficient mismatched substrates," Science, vol. 272, no. 5260, pp. 396-398, 1996.

[9] S. Kubelka, R. Haubner, B. Lux, R. Steiner, G. Stingeder, and M. Grasserbauer, "Influences of WC-Co hard metal substrate pre-treatments with boron and silicon on low pressure diamond deposition," Diamond and Related Materials, vol. 3, no. 11-12, pp. 1360-1369, 1994.

[10] T. Li, Q. Lou, J. Dong, Y. Wei, and J. Liu, "Modified surface morphology in surface ablation of cobalt-cemented tungsten carbide with pulsed UV laser radiation," Applied Surface Science, vol. 172, no. 3-4, pp. 331-344, 2001.

[11] M. Barletta, G. Rubino, and A. Gisario, "Co removal and phase transformations during high power diode laser irradiation of cemented carbide," Applied Surface Science, vol. 257, no. 9, pp. 4239-4245, 2011.

[12] M. Barletta, G. Rubino, and A. Gisario, "Adhesion and wear resistance of CVD diamond coatings on laser treated WC-Co substrates," Wear, vol. 271, no. 9-10, pp. 2016-2024, 2011.

[13] N. M. Everitt, R. F. Silva, J. Vieira, C. A. Rego, C. R. Henderson, and P. W. May, "Friction measurements on hot filament CVD diamond films deposited on etched tungsten carbide surfaces," Diamond and Related Materials, vol. 4, no. 5-6, pp. 730-734, 1995.

[14] M. G. Peters and R. H. Cummings, European Patent 0519587 A1, 1992.

[15] J. Miao, J. Song, Y. Xue, Y. Tong, W. Tang, and F. Lu, "Effect of a two-step pretreatment method on adhesion of CVD diamond coatings on cemented carbide substrates," Surface and Coatings Technology, vol. 187, no. 1, pp. 33-36, 2004.

[16] R. Polini, F. P. Mantini, M. Barletta, R. Valle, and F. Casadei, "Hot filament chemical vapour deposition and wear resistance of diamond films on WC-Co substrates coated using PVD-arc deposition technique," Diamond and Related Materials, vol. 15, no. 9, pp. 1284-1291, 2006

[17] S. K. Sarangi, A. Chattopadhyay, and A. K. Chattopadhyay, "Effect of pretreatment, seeding and interlayer on nucleation and growth of HFCVD diamond films on cemented carbide tools," International Journal of Refractory Metals and Hard Materials, vol. 26, no. 3, pp. 220-231, 2008.

[18] G. Cabral, J. Gäbler, J. Lindner, J. Grácio, and R. Polini, "A study of diamond film deposition on WC-Co inserts for graphite machining: effectiveness of $\mathrm{SiC}$ interlayers prepared 
by HFCVD," Diamond and Related Materials, vol. 17, no. 6, pp. 1008-1014, 2008.

[19] F. Fendrych, A. Taylor, L. Peksa et al., "Growth and characterization of nanodiamond layers prepared using the plasmaenhanced linear antennas microwave CVD system," Journal of Physics D, vol. 43, no. 37, Article ID 374018, 2010.

[20] S. D. Wolter, J. T. Glass, and B. R. Stoner, "Bias induced diamond nucleation studies on refractory metal substrates," Journal of Applied Physics, vol. 77, no. 10, pp. 5119-5124, 1995.

[21] E. R. Kupp, W. R. Drawl, and K. E. Spear, "Interlayers for diamond-coated cutting tools," Surface and Coatings Technology, vol. 68-69, pp. 378-383, 1994.

[22] C. R. Lin, C. T. Kuo, and R. M. Chang, "Improvement in adhesion of diamond films on cemented WC substrate with Ti-Si interlayers," Diamond and Related Materials, vol. 7, no. 11-12, pp. 1628-1632, 1998.

[23] K. Saijo, M. Yagi, K. Shibuki, and S. Takatsu, "Improvements in adhesive strength and cutting performance of diamondcoated tools," Surface and Coatings Technology, vol. 47, no. 1-3, pp. 646-653, 1991.

[24] E. J. Oles, A. Inspektor, and C. E. Bauer, "The new diamondcoated carbide cutting tools," Diamond and Related Materials, vol. 5, no. 6-8, pp. 617-624, 1996.

[25] T. Sato, Y. Hosokawa, S. Ito, and K. Akashi, "Plasma carbonitriding of cemented carbide substrate as an effective pretreatment process for diamond CVD," Surface and Coatings Technology, vol. 112, no. 1-3, pp. 189-193, 1999.

[26] W. D. Man, J. H. Wang, Z. B. Ma, and C. X. Wang, "Plasma boronitriding of $\mathrm{WC}(\mathrm{Co})$ substrate as an effective pretreatment process for diamond CVD," Surface and Coatings Technology, vol. 171, no. 1-3, pp. 241-246, 2003.

[27] D. G. Lee, J. M. Fitz-Gerald, and R. K. Singh, "Novel method for adherent diamond coatings on cemented carbide substrates," Surface and Coatings Technology, vol. 100-101, no. 1-3, pp. 187-191, 1998.

[28] T. Li, Q. Lou, J. Dong, Y. Wei, and J. Liu, "Selective removal of cobalt binder in surface ablation of tungsten carbide hardmetal with pulsed UV laser," Surface and Coatings Technology, vol. 145, no. 1-3, pp. 16-23, 2001.

[29] L. Tiejun, L. Qihong, D. Jingxing et al., "Improved adhesion of diamond coating on cobalt-cemented tungsten carbide hardmetal by using pulsed-UV-laser substrate surface pretreatment," Applied Surface Science, vol. 193, no. 1-4, pp. 102119, 2002.

[30] P. C. Jindal, D. T. Quinto, and G. J. Wolfe, "Adhesion measurements of chemically vapor deposited and physically vapor deposited hard coatings on WCCo substrates," Thin Solid Films, vol. 154, no. 1-2, pp. 361-375, 1987.

[31] R. Polini, P. D’Antonio, S. Lo Casto, V. F. Ruisi, and E. Traversa, "Cutting performance and indentation behaviour of diamond films on Co-cemented tungsten carbide," Surface and Coatings Technology, vol. 123, no. 1, pp. 78-83, 2000.

[32] C. Wild, N. Herres, and P. Koidl, "Texture formation in polycrystalline diamond films," Journal of Applied Physics, vol. 68, no. 3, pp. 973-978, 1990.

[33] T. Schuelke, T. Witke, H. J. Scheibe et al., "Comparison of DC and AC arc thin film deposition techniques," Surface and Coatings Technology, vol. 120-121, pp. 226-232, 1999.

[34] R. Polini, M. Santarelli, and E. Traversa, "Nucleation and adhesion of diamond films on Co cemented tungsten carbide," Journal of the Electrochemical Society, vol. 146, no. 12, pp. 4490-4498, 1999.
[35] R. Polini, M. Barletta, and M. Delogu, "Fluidized bed micromachining and HFCVD of diamond films onto Co-cemented tungsten carbide (WC-Co) hardmetal slabs," Thin Solid Films, vol. 515, no. 1, pp. 87-94, 2006. 

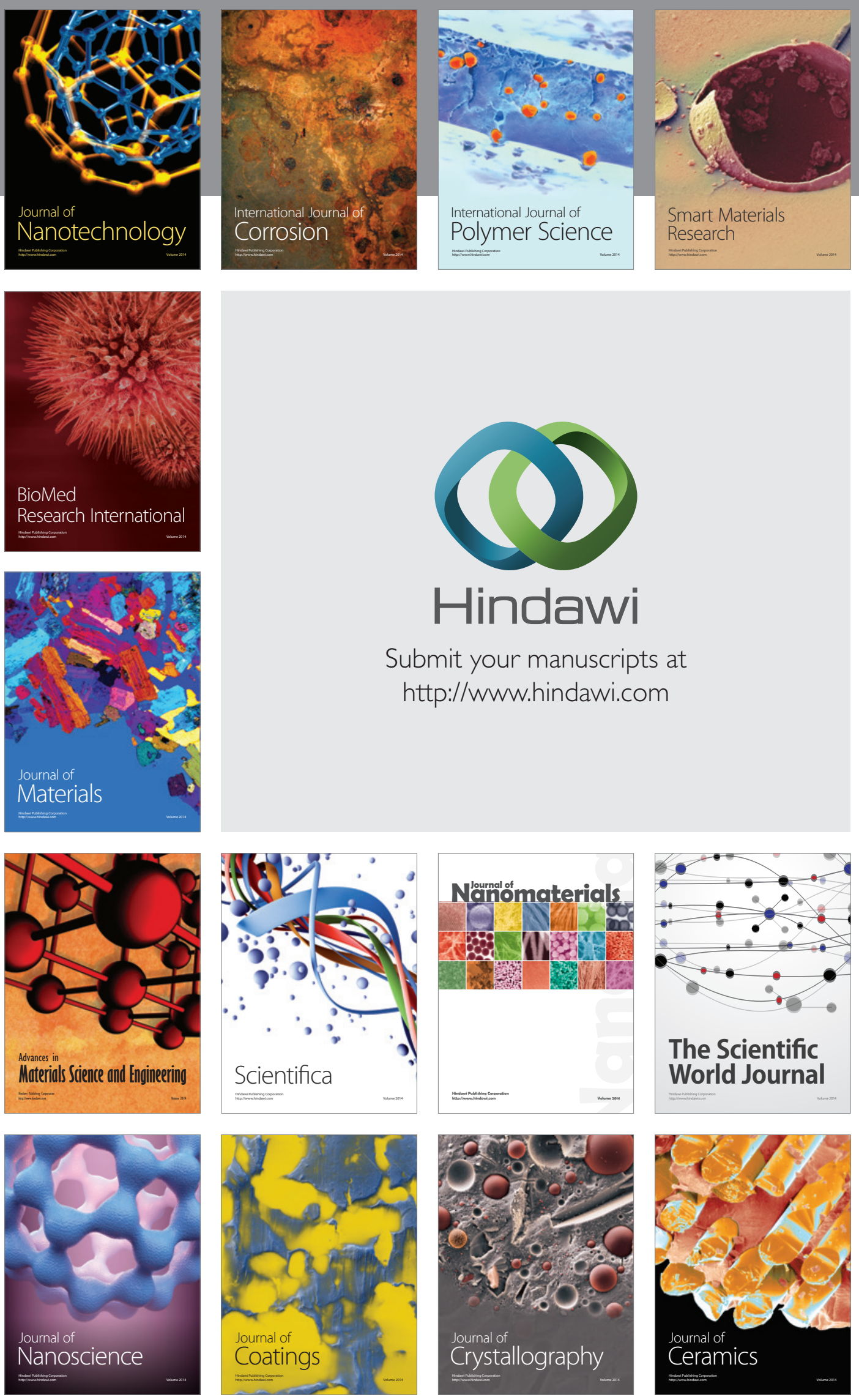

The Scientific World Journal

Submit your manuscripts at

http://www.hindawi.com

\section{World Journal}

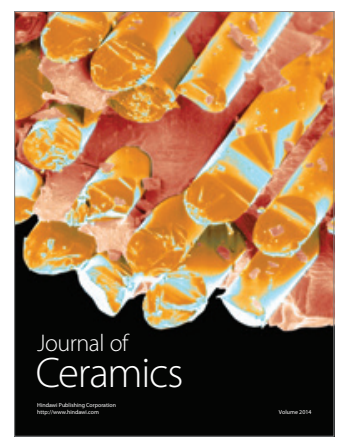

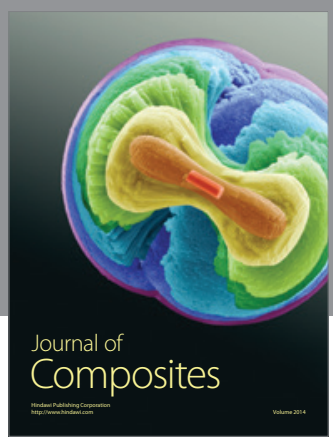
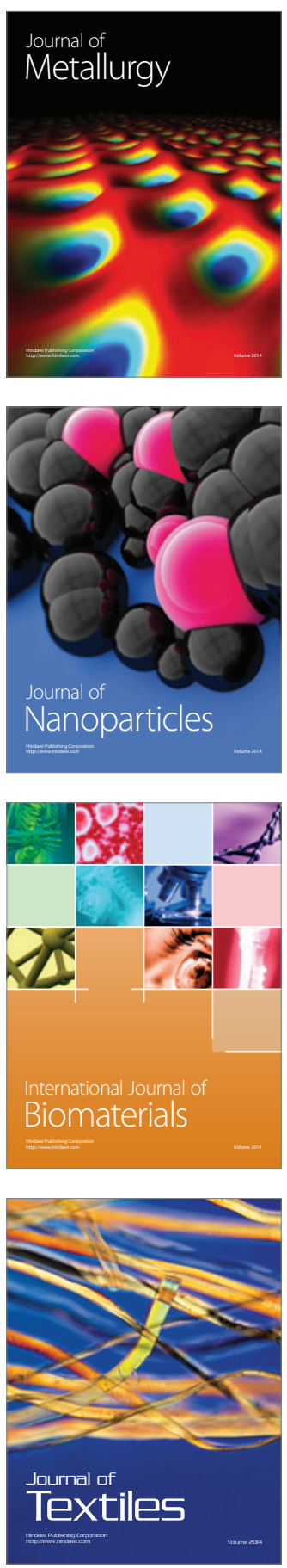